\title{
The AMS review: year 2
}

\author{
Victoria L. Crittenden • Robert A. Peterson
}

Received: 31 October 2012 / Accepted: 1 November 2012 /Published online: 13 November 2012

(C) Academy of Marketing Science 2012

\section{Theory development}

It has been over 5 years since the Academy of Marketing Science acknowledged the need in the marketing discipline for a conceptual/theoretical marketing journal. While marketing theories are tested regularly in our scholarly research, marketing scholars have been less prone to offer theoretical developments. Whether it is the lack of training in theory development, the time involved in developing theory, or various and sundry other rationale for the theoretical lacuna, the decline in conceptual/theoretical articles in marketing appears to be now well-recognized. Yet, theoretical articles contribute to marketing knowledge by explaining phenomena and relationships between phenomena and by positing and predicting relationships awaiting further investigation.

The genesis of the AMS Review was this recognition by the Academy of Marketing Science leadership that our discipline was underserved by existing journals when it came to conceptual/theoretical contributions. With that recognition evolved the aims and scopes of the Review:

...to publish thoughtful contributions that offer insights and perspectives extending knowledge and understanding of marketing-related phenomena. The Review is receptive to different philosophical perspectives and levels of analysis that range from micro to macro. Especially welcome are manuscripts that integrate research

V. L. Crittenden $(\bowtie)$

Carroll School of Management, Boston College, Fulton Hall 450B,

140 Commonwealth Ave,

Chestnut Hill, MA 02467, USA

e-mail: victoria.crittenden@bc.edu

R. A. Peterson

Office of the Vice President for Research, The University of Texas at Austin, Austin, TX 78713, USA

e-mail: rap@mail.utexas.edu and theory from non-marketing disciplines such as management, sociology, economics, psychology, geography, anthropology, or other behavioral sciences. Examples of suitable manuscripts include those incorporating conceptual and organizing frameworks or models; those extending, comparing, or critically evaluating existing theories or models; and those suggesting new or innovative theories or models. Comprehensive and integrative quantitative syntheses of research literatures (i.e., meta-analyses) are appropriate.

In meeting these goals, the AMS Review does not publish empirically-based research, which is consistent with the Academy of Management Review and Psychological Review. Such empirically-based research is targeted to our sister journal, the Journal of the Academy of Marketing Science. While the Review is clear on not considering empirically-based research, the lack of agreement on what constitutes theory has enabled a wide range of possibilities for publication in the Review over the past 2 years. However, according to Hunt (1983), there are three criteria that distinguish a theoretical contribution from a nontheoretical contribution: (1) the systematically related criterion, (2) the lawlike generalizations criterion, and (3) the empirically testable criterion. The articles that have appeared in these first 2 years of the Review adhere to Hunt's conditions, while offering a wide variety of concepts and contexts for future examination.

\section{The culmination of years 1 and 2}

In October of 2012, exactly 100 papers had been fullyprocessed at the AMS Review. While that number is nowhere near the processed numbers of long-time journals in marketing, it represents the scholarship of 100 author teams 
from around the world. Importantly, author teams that hope to contribute to marketing theory. The Academy of Marketing Science is particularly pleased with the countries represented by the lead author of each submitted manuscript (only lead author country is compiled in our databases). These lead authors have been from: Australia, Austria, Bosnia and Herzegovina, Brazil, Canada, Estonia, Finland, France, Germany, India, Iran, Ireland, Israel, Italy, Republic of Korea, Kuwait, Malaysia, The Netherlands, New Zealand, Nigeria, Pakistan, Portugal, South Africa, Sweden, Turkey, United Arab Emirates, United Kingdom, and United States of America. Thus, as marketers, we are exerting a global reach and engaging scholars from around the world in our mission to contribute to marketing theory.

As an open-access journal for the first 2 years, we have registered considerable activity with our online viewership. The most downloaded article over the past 2 years has been "Stakeholder Marketing: A Definition and Conceptual Framework" by the author team of Hult et al. (2011). As noted in the description of the AMS Review, the journal is not a repository for literature reviews. However, this article on stakeholder marketing showed the power that could result from linking an extensive literature review with established marketing theory so as to define a new construct in marketing. The author team established stakeholder marketing as a field of study by offering a conceptual framework for understanding the pivotal role of the construct in examining the linkages among stakeholder exchanges, value creation, and marketing outcomes.

While the Hult et al. (2011) article experienced immediate and sustained downloads, the online activity on the journal's Springer website has been remarkable. With Online First, accepted manuscripts are available almost instantly for scholarly access. This instantaneous access enables the sharing of knowledge such as the article by Samson and Voyer in this issue that had around 100 downloads within the first week of online availability.

During the first 2 years of publication, the Review has published articles from several well-known and prominent marketing theorists. As well, the journal has welcomed contributions from relatively new theory developers. These contributors represent both the spectrum of marketing scholars (e.g., strategy, consumer behavior/psychology, public policy, services, communications) and the reach of marketing (e.g., entrepreneurship, corporate/organizational identity, moral philosophy).

Wrapping up this second year of publication are five articles. These five articles represent various topical areas. We begin this issue with the consumer psychology article by Samson and Voyer (2012). Importantly, the authors show how duality models can help us understand implicit and explicit attitude formation in consumer psychology. Next is a comprehensive article on identity theories by Lam (2012). The article reviews the nature and causes of controversies within the study of identity-motivated marketing relationships. Berthon and Pitt (2012) then offer a theory of spoof advertising based on the literatures of burlesque, satire, and caricature. Combining scholarly interest in culturally-driven determinants of ethical behavior with generational subculture theory, the author team of Robertson et al. (2012) offer a framework for cross-cultural researchers. Finally, we wrap up this issue with an article that seems to have taken a life of its own. In 2011, we published an article by Karande et al. (2011). Unfortunately, at that time, the uncorrected page proofs of the article had been inadvertently posted online. The published copy in Volume 1, Issue 2 was the corrected copy. However, the only way to clear the page proofs from the online world is to move it to print copy. While this does not make sense to many of us, we are publishing the uncorrected version of the article in this issue. Interestingly, this version of the article receives regular downloads, so we know that many scholars are accessing the content. This is not a problem as the content is correct; there are just formatting errors in the tables. Thus, we find ourselves trying to bend to the power of the online publishing world - a world in which editors and publishers have little control.

As the inaugural issue of the AMS Review almost 2 years ago offered multiple approaches to crafting marketing theory, the articles in this issue offer a variety of topics, approaches, and themes. Each of the articles has the potential to make a significant contribution to theory development in marketing, albeit with a different framework and format for developing its theoretical contribution. As evidenced throughout the brief history of the Review, there is no one best way to craft marketing theory.

\section{Looking ahead}

Going forward, we hope to continue to attract diverse views of theory development from both marketing and nonmarketing disciplines. We know that our field is richer due to the plethora of global contributions that we have seen at the AMS Review. The AMS Review is an exemplar of the Academy of Marketing Science's mission to promote high standards and excellence in the creation and dissemination of marketing knowledge.

\section{References}

Berthon, P.R., \& Pitt, L.F. (2012). Brands and burlesque: toward a theory of spoof advertising. AMS Review, 2(2,3,4). 
Hult, G. T. M., Mena, J. A., Ferrell, O. C., \& Ferrell, L. K. (2011). Stakeholder marketing: a definition and conceptual framework. AMS Review, 1(1), 44-65.

Hunt, S. D. (1983). Marketing theory: the philosophy of marketing science. Homewood: Richard D. Irwin, Inc.

Karande, K., Merchant, A., \& Sivakumar, K. (2011). Relationships among time orientation, consumer innovativeness, and innovative behavior: the moderating role of product characteristics. AMS Review, 1(2), 99-116.
Lam, S.K. (2012). Identity-motivated marketing relationships: research synthesis, controversies, and research agenda. AMS Review, 2 $(2,3,4)$.

Robertson, C.J., Ralson, D.A., \& Crittenden, W.F. (2012). The relationship between cultural values and moral philosophy: a generational subculture theory approach. AMS Review, $2(2,3,4)$.

Samson, A., \& Voyer, B.G. (2012). Two minds, three ways: dual system and dual process models in consumer psychology. AMS Review, 2(2,3,4). 